\title{
Aminophylline as anti-hypoxic add-on therapy in the management of COVID-19 in Baghdad: An experience from single center report case study
}

\author{
Jamal Mawlood KHALAF1 (D), Ismail Ibrahim HUSSEIN 2 (D), Marwan Salih AL-NIMER 3* (D) \\ 1 Respiratory Center, Army Force Hospital, Baghdad, Iraq. \\ 2 Department of Physiology, College of Medicine, Al-Mustansiriya University, Baghdad, Iraq. \\ 3 Department of Pharmacology, College of Medicine, University of Diyala, Baqubah, Iraq. \\ * Corresponding Author. E-mail: alnimermarwan@ymail.com (M.S.A), Tel. +964-790-260 0291.
}

Received: 17 December 2020 / Revised: 29 October 2021 / Accepted: 31 October 2021

\begin{abstract}
Coronavirus has affected people of all ages, gender, and various health status. Persons with chronic diseases or other health conditions may have severe illness from COVID-19. There is no specific drug targeting the coronavirus. Aminophylline is a phosphodiesterase enzyme inhibitor that stimulates the respiratory center and peripherally relaxes the bronchial smooth muscle, which explain its anti-hypoxic effect. This study aimed to show the effect of aminophylline as an anti-hypoxic agent as add-on therapy to the high flow rate oxygen in COVID-19 patients who presented with low blood oxygen. This case managemnt study was carried out in the Army Force HospitalRespiratory Centre from 10th April-20thAugest 2020. Thirty-one patients with severe COVID-19 illness were treated with aminophylline (250-500 mg, slow intravenous infusion, per day) after 2-5 days of respiratory distress. Aminophylline therapy is effective in relieving the hypoxia by elevating the blood saturation with oxygen in $100 \%$ ( 10 out of 10 patients) in COVID-19 patients without evidence of risk factors or concomitant diseases. The effectiveness of aminophylline declined to $81.9 \%$ in patients with concomitant diseases, and it was ineffective in 4 patients, three of them survived with artificial ventilation, and one of them was died despite using all supportive measures. In conclusion, Aminophylline as anti-hypoxic agent is associated with improved outcome in severe COVID-19. Its effect is extended to patients with risk factors or concomitant diseases.
\end{abstract}

KEYWORDS: COVID-19; aminophylline; antihypoxic; survival rate.

\section{INTRODUCTION}

Different pharmacological interventions are used in the management of coronavirus disease (COVID19), and none of them showed a specific promising effect that terminates the illness within a short period and without adverse reactions [1]. Symptomatic treatment proved to be effective and can be considered as lifethreatening measures, including oxygen supplementation, antipyretic agents, antitussives, antibacterial agents in case of secondary infections...and so on [2]. The efficacy of short-acting or long-acting beta-2 adrenoceptor agonists is not assessed precisely in the management of COVID-19 because bronchospasm is not a clinical feature of coronavirus infection [3,4]. However, salbutamol metered-dose inhaler is a suitable medicine in the management of COVID-19 with respiratory distress [5]. There is clinical evidence that longacting beta-2 agonists can improve the diffusive lung property in chronic obstructive lung disease, which may be useful in COVID-19 as the gas diffusion capacity of the lung is impaired [6, 7]. Aminophylline is a bronchodilator that acts by inhibiting the phosphodiesterase enzyme inhibitor leading to an increase in the intracellular level of cyclic adenosine monophosphate which producing a dilatation of the bronchial tree. Several studies showed that aminophylline has pleiotropic effects, including anti-inflammatory [8], antioxidant [9], and anti-hypoxia [10]. It relieves the symptoms associated with hypoxia-like headache and effectively alleviates the hypoxia when it is concomitantly used with other medicine [10]. In addition, it improves the respiratory muscles, and thereby reduces the status of hypercapnia associated with hypoxia [11]. In one case study, including three neonates who presented with severe acute respiratory syndrome coronavirus infection, aminophylline as a symptomatic treatment improved the clinical features of COVID-19 [12]. The rationale of this study is to evaluate the efficacy of aminophylline in COVID-19 patients as an anti-

How to cite this article: Khalaf JM, Hussein II, Al-Nimer MS. Aminophylline as anti-hypoxic add-on therapy in the management of COVID-19 in Baghdad: An experience from single center report case study. J Res Pharm. 2021; 25(6): 852-856. 
hypoxic agent rather than as a bronchodilator. The aim of this case management study is to show the clinical effect of using aminophylline as anti-hypoxic on the clinical features of COVID-19 patients

\section{RESULTS}

In this case management study, a thirty-one patient presented with COVID-19 and severe hypoxia $\left(\mathrm{SaO}_{2}\right.$ $<90 \%$ ) were treated with intravenous infusion of aminophylline as an anti-hypoxic agent. The characteristics of patients showed the mean \pm SD of age was $55.5 \pm 13.2$, with a wide range (Table 1). The cardinal clinical features of COVID-19 were fever, cough, dyspnea, and headache (Table 1). Two patients complained from diarrhea and another two patients had disturbances of consciousness. The highest frequency of diseases that associated with COVID-19 are those related to cardiovascular diseases (e.g. hypertension, obesity, ischemic and valvular heart diseases, and smoking) (Table 1). Diseases linked to the respiratory system e.g. bronchial asthma, and chronic obstructive pulmonary disease uncommonly complicated by COVID-19 (Table 1). Twenty-seven out of 31 patients $(87.1 \%)$ responded to aminophylline as add-on therapy to the high flow rate of oxygen; 10 of them were without risk factor or concomitant disease (Figure 1). Four out of 31 patients did not show response to aminophylline and high flow rate oxygen; two females and two males. Patients with poor outcomes despite administration of aminophylline, had risk factors and/or disease (Table 2). The mortality rate was 1 out of $31(3.2 \%)$.

Table 1. Characteristics of the 31-patients with COVID-19.

\begin{tabular}{ll}
\hline Variables & Results \\
\hline Sex (male: female) & $25: 6$ \\
Age (year) & \\
Mean \pm SD & $55.5 \pm 13.2$ \\
Median (Inter-quarter) & $59(50-64.5)$ \\
Clinical presentation & \\
Fever & \\
Cough & $31(100)$ \\
Dyspnea & $27(87.1)$ \\
Headache & $31(100)$ \\
Diarrhea & $14(45.2)$ \\
Disturbances of consciousness & $2(6.5)$ \\
Risk factors & $2(6.5)$ \\
Current smoking & \\
Obesity & $8(25.8)$ \\
Hypertension & $2(6.5)$ \\
Diabetes Mellitus & $13(41.9)$ \\
Ischemic heart disease & $14(45.2)$ \\
Valvular Heart disease & $4(12.9)$ \\
Bronchial asthma & $1(3.2)$ \\
Chronic pulmonary obstructive lung disease & $3(9.7)$ \\
Rheumatoid arthritis & $1(3.2)$ \\
\hline The results are expressed as number (percentage) &
\end{tabular}

\section{DISCUSSION}

This case management study shows that the initiation of aminophylline intravenous infusion within 25 days of onset of severe hypoxia in patients with Covid-19 can accelerate the recovery of patients from the disease. The effectiveness of aminophylline in COVID-19 is reduced from $100 \%$ in patients without risk factor to $81 \%$ in patients with risk factors and/or concomitant diseases. Aminophylline is prescribed as an antihypoxic, not as a bronchodilator, to facilitate the action of a high flow rate of oxygen and elevates the blood saturation with oxygen. The dose of aminophylline $(250-500 \mathrm{mg}$, daily) that is used in this study is safe and it does not cause a significant adverse reaction [9]. In experimental animal studies, aminophylline infusion as add-on therapy improved the oxygenation in the experimental model of meconium syndrome [13]. Moreover, aminophylline has two important pharmacological actions (enhances the contraction of the diaphragm muscle, and stimulates the respiratory center) that play a role in improving blood oxygenation [14]. Recent studies reported that COVID-19 disease is an inflammatory disease associated with a significantly high level 
of interleukin-6 $[15,16]$. Tamburro et al reported that aminophylline significantly reduced the serum IL-6 in critically ill children admitted in the intensive care unit, and the anti-inflammatory effect of aminophylline is associated with clinical improvement [17]. Patients with concomitant morbidity are less likely to respond to aminophylline, and this finding agreed with other studies that found the severity of COVID-19 is increased in diabetic patients compared with those without diabetes [18]. In silico study from Saudi Arabia showed that, molecular docking of the coronavirus proteins are interacted with theophylline, remdesivir, and lopinavir, indicating that theophylline has a specific anti-coronavirus effect [19]. Other in silico study found that theophylline has the ability to bind to the RNA binding region on the N protein of coronavirus, suggesting that theophylline has a direct antiviral effect besides its effects on the respiratory system [20]. Therefore, the findings of this clinical study confirmed the current in silico computational studies. One of the most important limitations of the study is this study is uncontrolled, which is impossible to carry a placebo-controlled study on COVID-19 in a single center in the Middle East countries.

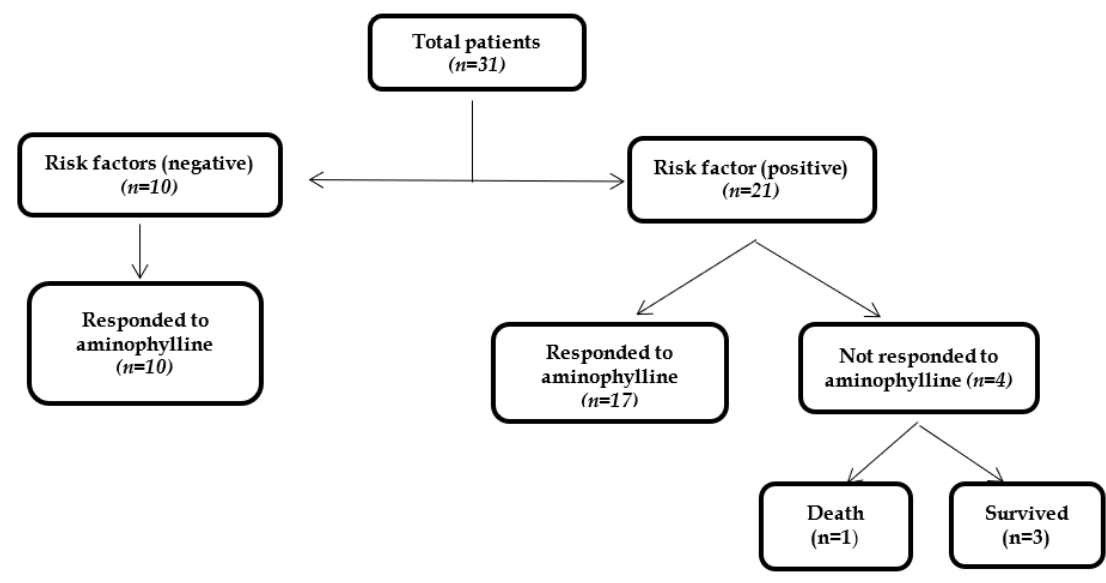

Figure 1. Schematic diagram showed the outcome of using aminophylline as antihypoxic in the management of COVID-19 patients with low oxygen blood saturation.

Table 2. Characteristic features of four patients with poor outcomes despite aminophylline therapy.

\begin{tabular}{ll}
\hline Variables & Results \\
\hline Sex (male: female) & $2: 2$ \\
Age (year) & \\
Clinical presentation & 4 \\
Fever & 4 \\
Cough & 4 \\
Dyspnea & 3 \\
Headache & 0 \\
Diarrhea & 1 \\
Disturbances of consciousness & \\
Risk factors & 0 \\
Current smoking & 1 \\
Obesity & 2 \\
Hypertension & 2 \\
Diabetes Mellitus & 1 \\
Ischemic heart disease & 1 \\
Valvular Heart disease & 0 \\
Bronchial asthma & 0 \\
Chronic pulmonary obstructive lung disease & 1 \\
Rheumatoid arthritis & \\
\hline
\end{tabular}

\section{CONCLUSION}

Aminophylline as add on therapy to high rate oxygen flow accelerates the recovery of patients from COVID-19 by having an anti-hypoxic effect. This study confirmed current studies that phosphodiesterase enzyme inhibitors are useful in the management of viral diseases including coronavirus. 


\section{MATERIALS AND METHODS}

This case management study was performed in the Army Force Hospital-Respiratory Centre in Baghdad from $10^{\text {th }}$ April-20 th August 2020. This study was approved by the Ethical committee at the Army Force Hospital (No.270, dated 01-04-2020). Patients who presented with clinical signs and symptoms suggestive of COVID-19, and confirmed by polymerase chain reaction, and radiological examination, including chest $\mathrm{X}$-ray and computerized tomography of the lung. The patients were allocated randomly using randomized tables. The inclusion criteria were patients with COVID-19 and presented with severe hypoxia (Hypoxia was defined as the blood oxygen saturation of $<93 \%$ ), and radiological features indicating respiratory distress syndrome. The percentage of blood oxygenation was determined by Plus Oximeter. A total number of 31 patients ( 25 males and 6 females) were included in this case management study. Each patient according to his/her clinical conditions was treated with a slowly intravenous aminophylline infusion (250-500 mg, daily). Aminophylline was added to a pint of a glucose-saline solution, and a drip was running at a rate of $4 \mathrm{ml}$ per minutes. All the patients were treated with antiviral (Favipiravir, $800 \mathrm{mg}$ twice daily for 5 days) anticoagulant (Enoxaparin,6000 IU/day, Dexamethasone 6mg/day), antimicrobials whenever there was evidence of bacterial infection, symptomatic treatment for headache, fever, and cough. The high flow rate of oxygen $(10-15 \mathrm{~L} / \mathrm{min})$, and aminophylline was used as add-on-therapy after 2-5 days of deterioration of the general health and severe dyspnea (saturated oxygen $<90 \%$ ). The characteristic data including, the clinical features, risk factors, presence of concomitant illnesses were recorded. All the patients were monitored, and and patients who did not respond to aminophylline or whose saturated blood oxygen dropped to $<90 \%$ were admitted into the intensive care unit, where they were managed with mechanical ventillator. Excel 2010 software program was used for analyzing the data. The results are expressed as frequencies, percentages, and whenever possible as mean \pm SD.

Acknowledgements: The authors thank all the people in the hospital, including the patients, medical staff, and the professionals for their kindly help to perform this study.

Author contributions: Concept - J.M.K., M.S.A-N.; Design - J.M.K., I.I.H..; Supervision - J.M.K.; Resources - J.M.K., I.I.H.; Materials - J.M.K.; Data Collection and/or Processing - J.M.K., I.I.H.; Analysis and/or Interpretation - M.S.A-N.; Literature Search - M.S,A-N., J.M.K.; Writing - M.S.A-N., J.M.K.; Critical Reviews - J.M.K.,M.S.A-N.,I.I.H.

Conflict of interest statement: The authors declare no conflict of interest in the manuscript.

Ethics Committee Aproval: All procedures conducted in this study were approved by Ethical Committee of the Army Force Hospital in Baghdad, Iraq with the approval number of 270/01-04-2020.

\section{REFERENCES}

[1] Esposito S, Noviello S, Pagliano P. Update on treatment of COVID-19: ongoing studies between promising and disappointing results. Infez Med. 2020; 28(2): 198-211.

[2] Wiersinga WJ, Rhodes A, Cheng AC, Peacock SJ, Prescott HC. Pathophysiology, transmission, diagnosis, and treatment of coronavirus disease 2019 (COVID-19): A review. JAMA. 2020; 324(8): 782-793. [CrossRef]

[3] Wong AW, Fidler L, Marcoux V, Johannson KA, Assayag D, Fisher JH, Hambly N, Kolb M, Morisset J, Shapera S, Ryerson CJ. Practical considerations for the diagnosis and treatment of fibrotic interstitial lung disease during the coronavirus disease 2019 pandemic. Chest. 2020; 158(3): 1069-1078. [CrossRef]

[4] Mo X, Jian W, Su Z, Chen M, Peng H, Peng P, Lei C, Chen R, Zhong N, Li S. Abnormal pulmonary function in COVID19 patients at time of hospital discharge. Eur Respir J. 2020; 55(6): 2001217. [CrossRef]

[5] Elbeddini A. Sterilization plan of the used metered dose inhalers (MDI) to avoid wastage amid COVID-19 pandemic drug shortage. J Pharm Policy Pract. 2020; 13: 19. [CrossRef]

[6] Di Marco F, Guazzi M, Sferrazza Papa GF, Vicenzi M, Santus P, Busatto P, Piffer F, Blasi F, Centanni S. Salmeterol improves fluid clearance from alveolar-capillary membrane in COPD patients: a pilot study. Pulm Pharmacol Ther. 2012; 25(1): 119-123. [CrossRef]

[7] Ye ZW, Jin DY. Diagnosis, treatment, control and prevention of SARS-CoV-2 and coronavirus disease 2019: back to the future. Sheng Wu Gong Cheng Xue Bao. 2020; 36(4): 571-592.[CrossRef]

[8] Luo WJ, Ling X, Huang RM. Effects of aminophylline on cytokines and pulmonary function in patients undergoing valve replacement. Eur J Cardiothorac Surg. 2004; 25(5): 766-771. [CrossRef] 
[9] Yang B, Wang GY, Chen B, Qin RB, Xi SL, Chen L. Anti-hypoxia and anti-oxidation effects of aminophylline on human with acute high-altitude exposure. Chin Med Sci J. 2007; 22(1): 62-65.

[10] Schroeder T, Piantadosi CA, Natoli MJ, Autmizguine J, Cohen-Wolkowieczs M, Hamilton KL, Bell C, Klawitter J, Christians U, Irwin DC, Noveck RJ. Safety and ergogenic properties of combined aminophylline and ambrisentan in hypoxia. Clin Pharmacol Ther. 2018; 103(5): 888-898. [CrossRef]

[11] Yokoba M, Katagiri M, Ichikawa T, Takakura A, Ishii N, Kurosaki Y, Yamada Y, Tsukushi T, Masuda N, Easton PA, Nishii Y, Okada Y, Abe T. Aminophylline increases respiratory muscle activity during hypercapnia in humans. Pulm Pharmacol Ther. 2015; 30: 96-101. [CrossRef]

[12] Dima M, Enatescu I, Craina M, Petre I, Iacob ER, Iacob D. First neonates with severe acute respiratory syndrome coronavirus 2 infection in Romania: Three case reports. Medicine (Baltimore). 2020; 99(3): e21284. [CrossRef]

[13] Shao JI, Lin CH, Yang YH, Jeng MJ. Effects of intravenous phosphodiesterase inhibitors and corticosteroids on severe meconium aspiration syndrome. J Chin Med Assoc. 2019; 82: 568-575. [CrossRef]

[14] Nair P, Milan SJ, Rowe BH. Addition of intravenous aminophylline to inhaled beta(2)-agonists in adults with acute asthma. Cochrane Database Syst Rev 2012; 12(12): CD002742. [CrossRef]

[15] McGonagle D, Sharif K, O'Regan A, Bridgewood C. The role of cytokines including interleukin-6 in covid-19 induced pneumonia and macrophage activation syndrome-like disease. Autoimmun Rev. 2020; 19(6): 102537. [CrossRef]

[16] Zhang C, Wu Z, Li JW, Zhao H, Wang GQ. Cytokine release syndrome in severe COVID-19: interleukin-6 receptor antagonist tocilizumab may be the key to reduce mortality. Int J Antimicrob Agents. 2020; 55(5):105954. [CrossRef]

[17] Tamburro RF, Thomas NJ, Ceneviva GD, Dettorre MD, Brummel GL, Lucking SE. A prospective assessment of the effect of aminophylline therapy on urine output and inflammation in critically ill children. Front Pediatr. $2014 ; 2: 59$. [CrossRef]

[18] Singh AK, Gupta R, Ghosh A, Misra A. Diabetes in COVID-19: Prevalence, pathophysiology, prognosis and practical considerations. Diabetes Metab Syndr. 2020; 14(4): 303-310. [CrossRef]

[19] AlAjmi MF, Azhar A, Owais M, Rashid S, Hasan S, Hussain A, Rehman MT. Antiviral potential of some novel structural analogs of standard drugs repurposed for the treatment of COVID-19. J Biomol Struct Dyn. 2020; 39(17): 6676-6688. [CrossRef]

[20] Sarma P, Shekhar N, Prajapat M, Avti P, Kaur H, Kumar S, Singh S, Kumar H, Prakash A, Dhibar DP, Medhi B. Insilico homology assisted identification of inhibitor of RNA binding against 2019-nCoV N-protein (N terminal domain). J Biomol Struct Dyn. 2020: 39(8): 2724-2732. [CrossRef] 